\title{
Co-existing of craniofacial fibrous dysplasia and cerebrovascular diseases: a series of 22 cases and review of the literature
}

Xiaowen Song ${ }^{1,2}$ and Zhi $\mathrm{Li}^{1,2^{*}}$

\begin{abstract}
Background: Craniofacial fibrous dysplasia is a fairly rare condition. Some literature have reported a few patients with craniofacial fibrous dysplasia suffering from vascular abnormalities. This study aimed to describe the possible coexistence of craniofacial fibrous dysplasia and cerebrovascular diseases for the first time.

Method: We retrospectively reviewed the 1175 patients with craniofacial fibrous dysplasia in Beijing Tiantan Hospital and the information of the 22 patients coexisted with cerebrovascular diseases were described. In addition, we performed a systematic review for cases of craniofacial fibrous dysplasia with vascular abnormalities.

Result: 22 out of 1175 patients (1.9\%) were diagnosed with craniofacial fibrous dysplasia and cerebrovascular diseases including 9 intracranial aneurysms, 4 venous malformations, 2 arteriovenous malformations, 1 moyamoya disease, 2 intracranial venous stenosis and 4 cerebral ischemia with a mean age of 38.18 years old. Only 2 patients were managed surgically for craniofacial fibrous dysplasia and 6 patients were treated with neurosurgery for cerebrovascular diseases. 8 patients were closely followed and only 1 patient's symptoms worsened.

Conclusion: Craniofacial fibrous dysplasia might cause constriction of the intracranial vessels and alteration of the overall hemodynamics of the intracranial vasculature resulting in various cerebrovascular diseases. Multimodal screening and examinations seems reasonable for patients with craniofacial fibrous dysplasia for throughout treatment and prognosis evaluations.
\end{abstract}

Keywords: Fibrous dysplasia, Cerebrovascular diseases, Coexistence, Interaction

\section{Background}

Fibrous dysplasia (FD) is a non-malignant condition in which normal bone and marrow are replaced by fibrous tissue and haphazardly distributed woven bone [1]. Patients may exhibit involvement of one bone (monostotic FD; MFD), multiple bones (polyostotic FD; PFD) or they may have McCune-Albright syndrome (MAS). The most common locations affected are the craniofacial bones, proximal femur, and rib [2], with the craniofacial

\footnotetext{
*Correspondence: Izsjwk@163.com

${ }^{1}$ Department of Neurosurgery, Beijing Tiantan Hospital, Capital Medical University, No 119, Nansihuan xilu, Beijing 100070, China

Full list of author information is available at the end of the article
}

region involved in $90 \%$ of the PED and MAS cases and the anterior cranial base involved in over $95 \%$ of these cases [3]. Depending on the type and location of FD, the signs and symptoms vary and include facial deformity and asymmetry, vision changes, hearing impairment, nasal congestion and/or obstruction, pain, paresthesia, and malocclusion.

Vascular abnormalities complicating FD has been reported in several case reports [4-10], suggesting that although there was no known common etiology, these two kinds of entities might be related to some extent. However, there was no literature focusing on the co-existence of craniofacial fibrous dysplasia (CFD) and cerebrovascular diseases (CVD), considering that the number original author(s) and the source, provide a link to the Creative Commons licence, and indicate if changes were made. The images or other third party material in this article are included in the article's Creative Commons licence, unless indicated otherwise in a credit line to the material. If material is not included in the article's Creative Commons licence and your intended use is not permitted by statutory regulation or exceeds the permitted use, you will need to obtain permission directly from the copyright holder. To view a copy of this licence, visit http://creativecommons.org/licenses/by/4.0/. The Creative Commons Public Domain Dedication waiver (http://creativeco mmons.org/publicdomain/zero/1.0/) applies to the data made available in this article, unless otherwise stated in a credit line to the data. 
of patients with CFD is pretty limited. Here we present a series of patients diagnosed with CFD coexisting with CVD which has been rare and never been reported before and the possible interactions and relationships between these two diseases were deduced, analyzed and discussed. And a literature review was done to further invest the coexistence of CFD and vascular diseases.

\section{Methods}

We retrospectively searched the radiological database in Beijing Tiantan Hospital and 1175 patients were found diagnosed with CFD radiologically during 2003-2020. And we further reviewed the medical records and radiological examinations of these 1175 patients. 22 patients coexisted with CVD were identified and were divided into the following two groups: hemorrhagic cerebrovascular diseases including intracranial aneurysm (IA) and vascular malformation and ischemic cerebrovascular diseases including vascular stenosis/occlusion and cerebral ischemia. All the CFD patients were diagnosed with classical radiological characteristics. And the clinical and radiological characteristics of these 22 patients were collected and described, and the possible relationships between the two diseases were discussed.

In addition, we searched 3 medical database, PubMed, EMBASE and Cochrane Library up to 2020 for published studies focusing on the coexistence of CFD and vascular diseases. The following combined terms ([MESH] "fibrous dysplasia" AND [MESH] "cerebrovascular diseases" or "intracranial aneurysm" or "cerebrovascular malformation" or "moyamoya disease" or "cerebral ischemia" or "intracranial hemorrhage"). A manual researching on the reference of identified studies was performed for more related studies.

This study was approved by Institutional Review Board of Beijing Tiantan Hospital, Capital Medical University. Due to the retrospective nature of our study, the board waived the need for written consent.

\section{Results}

\section{Clinical characteristics}

Of the 1175 FD patients evaluated, there were 22 patients (1.9\%) coexisted with CVD, with 15 falling into the hemorrhage group among whom 9 were diagnosed with IAs, 6 with cerebrovascular malformations (4 venous malformations and 2 arteriovenous malformations (AVMs)) and the other 7 divided into the ischemia group among whom 1 was diagnosed with moyamoya disease, 2 with intracranial venous sinus stenosis and 4 with cerebral ischemia. The mean age of two groups of patients was 37.27 (ranging from 6 to 65 ) and 40.14 years old (ranging from 25 to 56) respectively, with a mean age of 38.38 years old for all the included patients. Only $2(0.9 \%)$ were pediatric patients (aged $\leq 18$ years). The gender ratio was female: male $=1.9: 1$. Only 2 out of the 22 patients were treated with transnasal surgery for FD and 6 patients were managed surgically for cerebrovascular diseases. All of the patients were discharged home in good condition no matter what treatment was done. Chest-X ray and Echocardiography were screened for all the included patients and 2 patients were found to have anomalies of ribs indicating PFD. None of them had endocrinopathies or was diagnosed with MAS or other known FD related diseases such as breast cancer and intraductal papillary mucinous neoplasms (IPMNs). The detailed clinical information was presented in Table 1 and Table 2 .

\section{Radiological characteristics}

As shown in Table 1 and Table 2, sphenoid bone was the primary site effected by CFD $(15 / 22,68.2 \%)$. Most of the patients presented with slow-growing, painless masses resulting in facial or cranial asymmetry $(4 / 22,18.2 \%)$, and $15.79 \%(3 / 22,13.6 \%)$ have vision impairment related with FD of the sphenoid bones.

The position relationships of these two diseases were divided into 4 types: (1) neighboring; (2) displacement; (3) encircling; (4) unrelated. However, of the 9 patients with aneurysms, 6 showed impingement of contralateral internal carotid artery (ICA) instead of the ipsilateral ICA. By contrary, the radiological examinations of all of the 5 patients with cerebral ischemia showed impingement of ipsilateral ICA.

Eight patients were closely followed and most of the CFD stayed unchanged.

\section{Literature review}

Only four studies met the inclusion criteria, all of which were case reports. Two of them were arteriovenous fistulas (AVFs), one was AVM and the other one was middle meningeal artery aneurysm. Detailed information of these four articles were described in Table 3. Although these vascular anormalies seems to be closely related with the corresponding bone lesions, none of them was able to put forward a hypothesis to explain this kind of coexistence.

\section{Illustrative cases}

Case 1

Patient is a 53-year-old male who was admitted into hospital because of interval headache. His was diagnosed with IA for his magnetic resonance angiography (MRA), and Digital subtraction angiography (DSA) was done for a definite diagnosis showing right internal artery aneurysm measuring $7.14 \mathrm{~mm} * 5.63 \mathrm{~mm}$ (Fig. 1). At the same time, his magnetic resonance imaging (MRI) and computed tomography (CT) described the 


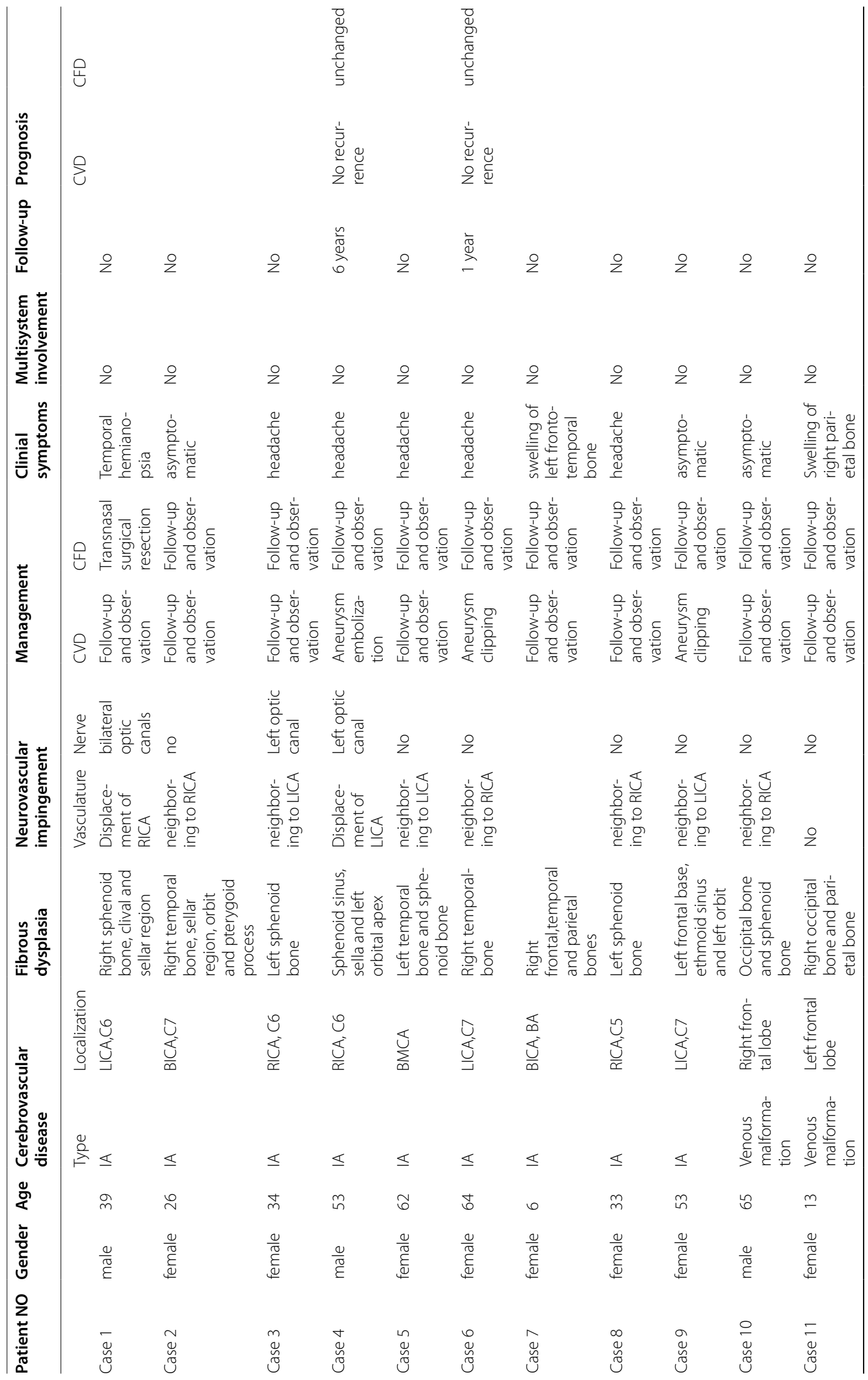




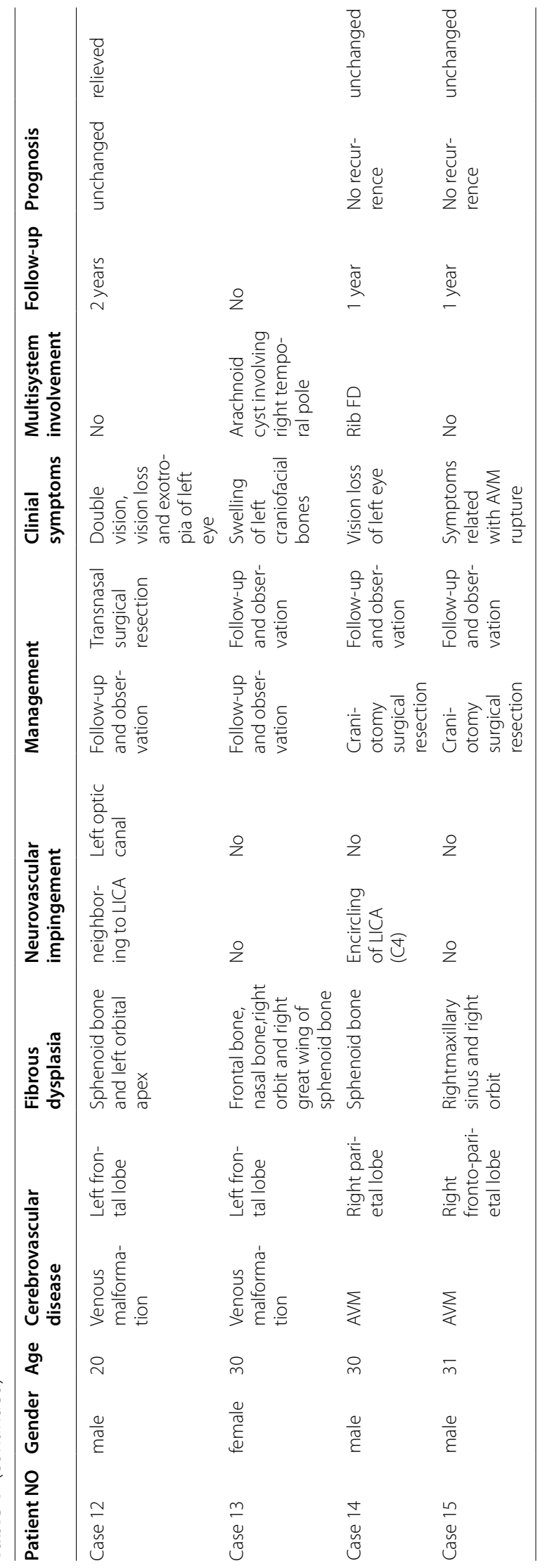




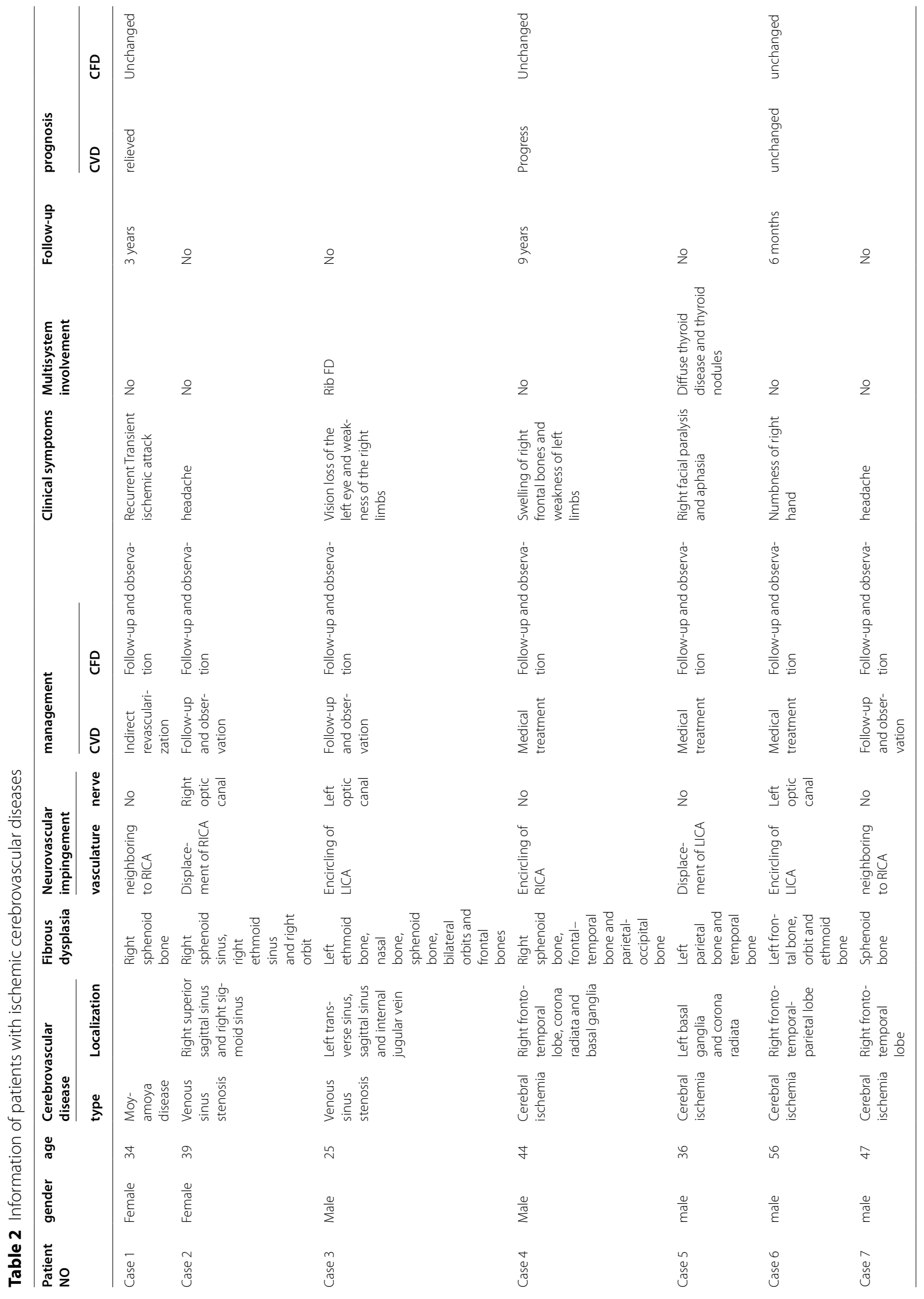


abnormal signals in his left sphenoid bone as FD and his colonoscopy found colonic vascular malformations. It was decided to manage the aneurysm with endovascular stent assisted coil embolization. 3 days after operation, the patient was discharged home in good condition. The patient was followed closely for six years and there was no sign of aneurysm recurrence or FD progress.

\section{Case 2}

Patient was a 20-year-old female complaining about double vision, vision loss and exotropia of left eye. Her $\mathrm{CT}$ scans described abnormalities of her left sphenoid bone and temporal bone with typical radiological characteristics of FD (Fig. 2). At the same time, her MRI showed a venous malformation in left frontal lobe. The FD was resected through transnasal approach, and the pathological reports confirm the FD diagnosis. During the 2-year follow-up, his symptoms partially relieved and no recurrence was found radiologically.

\section{Case 3}

Patient was a 30 year-old male who was transferred to the emergency department for sudden headache, hemiplegia and loss of consciousness three years ago. His CT scan showed intracranial hemorrhage in the right parietal lobe and eternal ventricular drainage was done emergently (Fig. 3). After his symptoms relieved, the DSA found an AVM which was resected. For pre-operation evaluation, MRI and chest X-ray were done showing FD of the left sphenoid bone and bilateral ribs. One week after surgery, the patient was discharged home in good condition. After 1-year follow-up, the patient fully recovered and the radiological examinations showed no recurrence of AVM or progress of FD.

\section{Case 4}

Patient was a 34-year-old female suffering from recurrent transient ischemia attacks. Her radiological characteristics conformed with moyamoya disease (Fig. 4). Right encephalo-duro-arterio-synangiosis was performed successfully and her post-operation CT showed FD of the right sphenoid bone. Nine days after surgery, the patient was discharged home. During the 3-year follow-up, her symptoms got better and her radiological examinations showed neovascularization without progress of FD.

\section{Case 5}

Patient was a 25-year-old male suffering from vision loss of left eye and weakness of right limbs. His CT scans showed extensive FD of left ethmoid bone, nasal bone, sphenoid bone, bilateral orbits and frontal bones with left brain tissue compressed and dislocated (Fig. 5). At the same time, the young patient was found to have FD of his 7th rib. MRA showed diffuse severe stenosis of venous sinuses of the left side. The patient was unwilling to receive any surgical treatment and was lost to follow-up.

\section{Case 6}

Patient was a 44-year-old female admitted to the emergency department due to left facial paralysis and weakness of left limbs. DWI showed acute cerebral ischemia of right fronto-parietal lobe (Fig. 6). MRA showed complete occlusion of the right internal artery and CT showed extensive craniofacial FD involving the right frontal bone, temporal bone, parietal bone and the occipital bone especially the right skull base. The male patient was managed conservatively with medical treatment with close follow-up for 9 years during which time he suffered from recurrent acute cerebral ischemia and MRI showed progress of brain ischemia involving right fronto-parietal lobe and right cerebellum.

\section{Case 7}

Patient was a 36-year-old male with chief complaint being aphasia and right facial paralysis. MRI showed acute cerebral ischemia of left basal ganglia (Fig. 7) and the patient was treated medically. However, the patient's symptoms remained the same. In addition, the ultrasound showed diffuse thyroid disease and multiple thyroid nodules. After 12 days in hospital, the patient was discharged home but was lost to follow-up.

\section{Discussion}

As we know, this article was the first report worldwide discussing the coexistence of the CFD and CVD. There might be three possible explanations for the coexistence: (1) genetic predisposition which means they may share something in common etiologically and pathophysiologically; (2) environmental influence that is to say one disease might have influence on the development, management and prognosis of the other; (3) chance occurrence thus having no mutual interaction.

CFD has been reported to be coexisted with some central nervous system diseases such as meningioma [11-13], plasmacytoma [14], Chondrosarcoma [15] and pituitary adenomas [16]. What's more, some literatures deduced that it was highly likely to cause neurovascular impingement [17]. Early in the twentieth century, Joseph et al. described the angiographic features of fibrous dysplasia of the skull in two patients including the local displacement of the vessels, abnormal vessel dilation, abnormal small beaded vessels, and arterial and venous 


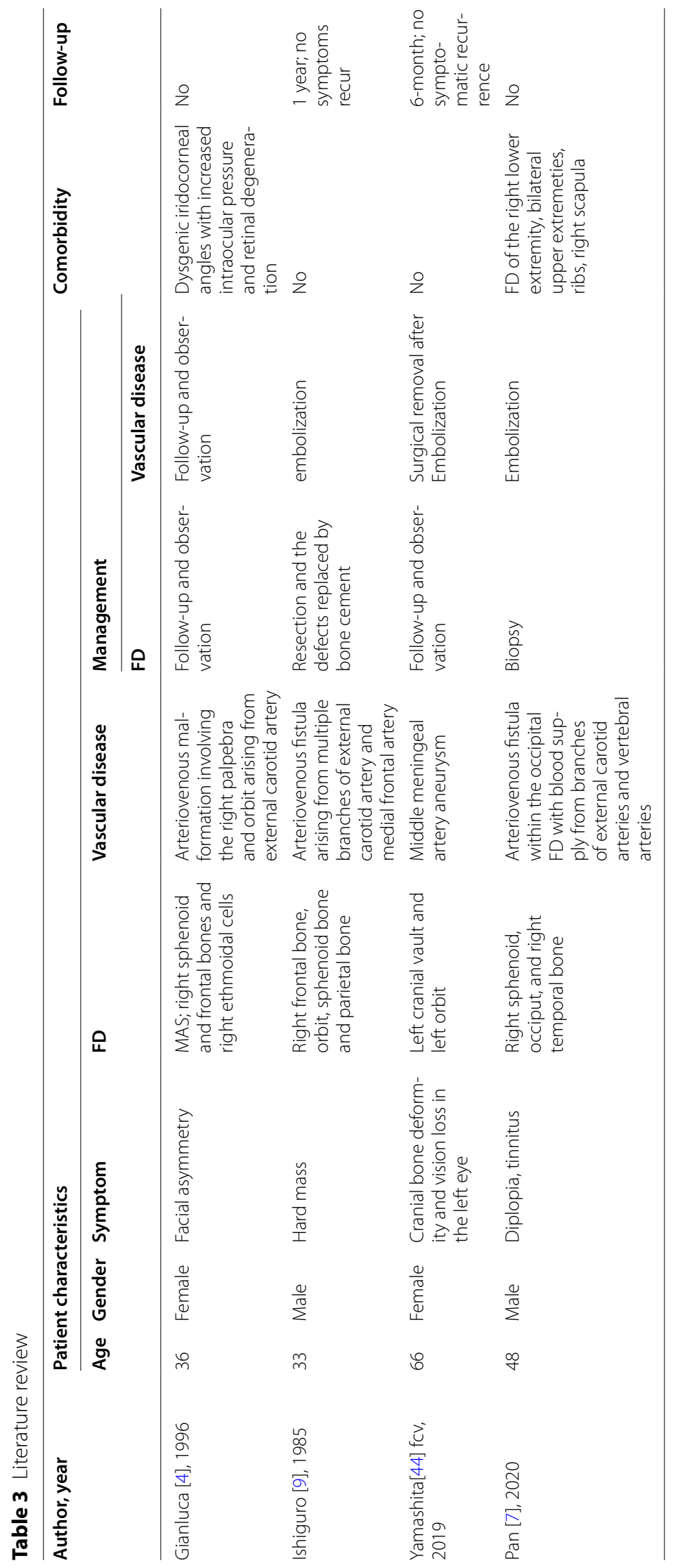




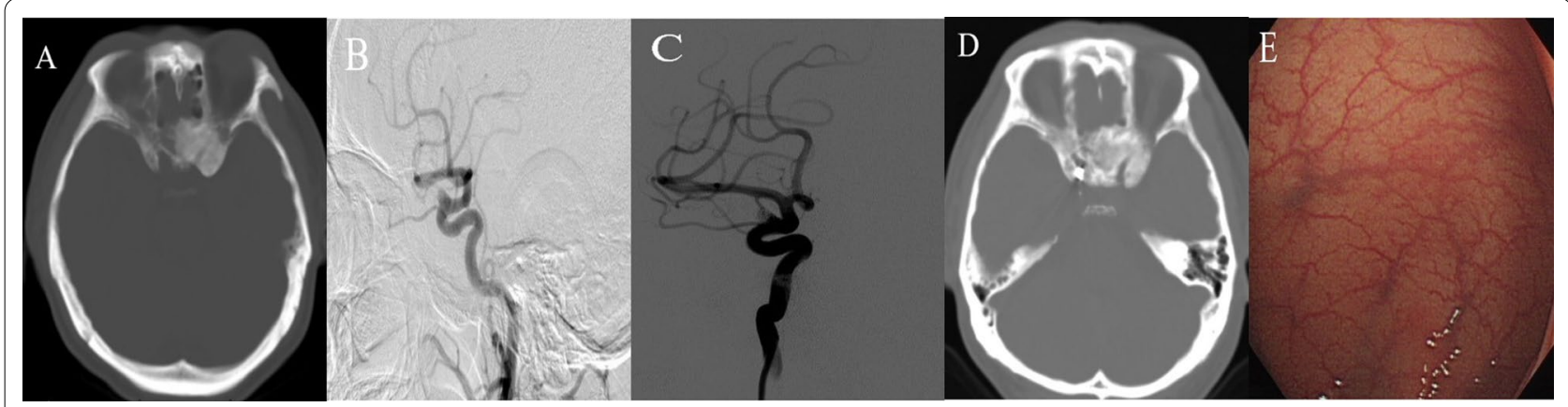

Fig. 1 CT showing FD of the left sphenoid bone (A) and DSA showing an aneurysm in the right internal carotid artery (C6) (B). Stent assisted coil embolization was done and there was no filling of aneurysm (C). After 6 years, his FD showed no sign of progression (D). At the same time, the patient was diagnosed with colonic vascular malformation by colonoscopy $(\mathbf{E})$

aneurysm formations [18]. Several case reports published describing FD coexisting with craniofacial vascular malformations such as occipital intraosseous AVF [7] and AVM involving the palpebra and orbit [4].

Our series covered almost all the clinical types of cerebrovascular diseases which is the first to focus on the relationship of CFD and vascular diseases. In our review of the previous case reports of this coexistence, which is pretty rare, all of the coexisted vascular diseases described were intraosseous AVF/AVM. And our series is fairly different.

Currently there are no known epidemiological or well-characterized genetic associations between CFD and CVD. FD arises from post-zygotic gain-of-function somatic mutations in the GNAS gene [19]. Multiple tissues may be affected leading to multiple clinical abnormalities including neurological abnormalities which are influenced by the time and developmental stage when these kind of mutations occur and by which parental allele becomes mutated [20, 21]. It has been proven that there is various heritable contributions to the pathogenesis of CVD. For instance, the formation of IAs are related with significant genetic heterogeneity especially CDKN2A-CDKN2BAS, ADAMTS, ELN, SOX17, HDAC9, EDNRA and so on [22-30]. And recurrently mutated genes were identified in several vascular malformations as well including TEK/TIE2 mainly in venous malformations [31], GNA11/14 mainly in vascular tumors [32], KRAS/NRAS/RASA1/HRAS mainly in AVMs [33], GNAQ [34], IDH1/2 [35], AKT1, PTEN and PIK3CA [36]. What's more, moyamoya diseases, which used to be considered as a rare polygenic cerebrovascular disease, is also known to be associated with some susceptibility genes especially RNF213 p.R4810K and human leukocyte antigen (HLA) [37]. Additionally, there is also a significant association of the RNF213 variant with ischemic stroke especially with cervical/intracranial large artery atherosclerosis [38]. These mutations are believed to be closely related with angiogenesis, inflammatory response [39], cell growth, proliferation, survival, and cell cycle progression [36]. As above, in respect of etiology, although the occurrence of FD and CVD such as

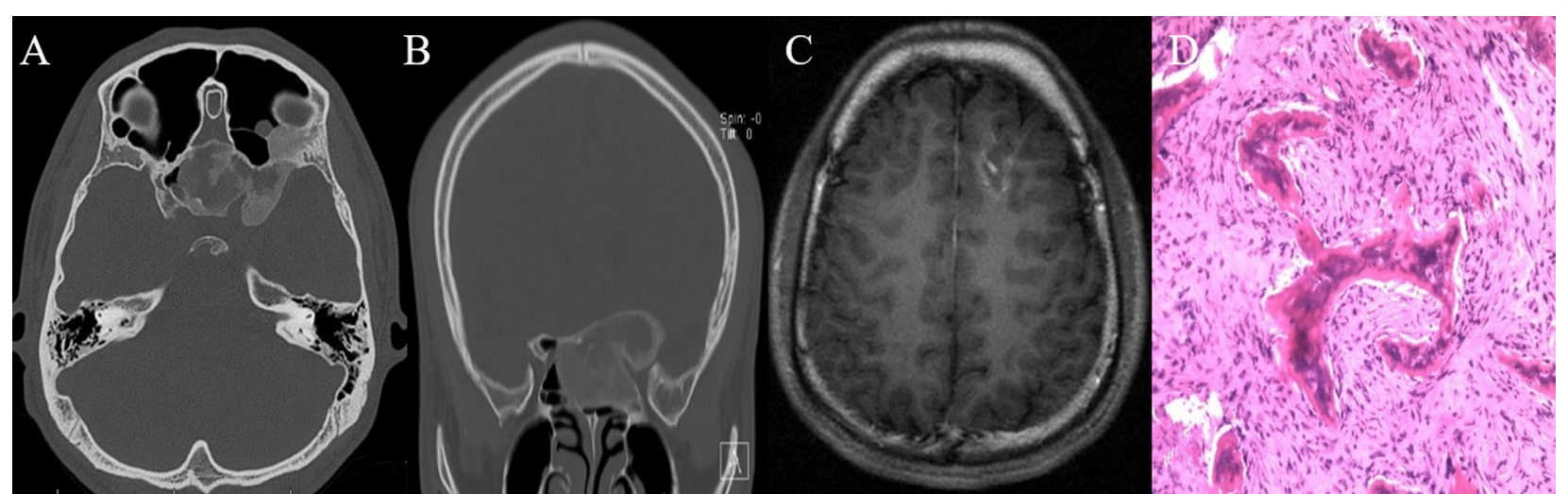

Fig. 2 CT showing FD of sphenoid bone and left orbital apex (A, B). MRI showing venous malformation of the left frontal lobe $(\mathbf{C})$. The patient's FD was managed with transnasal surgery and the pathological report confirmed the FD diagnosis (D) 
IAs, cerebral vascular malformations and moyamoya disease are supported to have something to do with the early gene mutations during embryo genesis [40], they may not share the same variant or the common pathophysiological pathway/mechanism.

When it comes to disease development, although no exact gene mutations is known to be shared by the two kinds of diseases, the fact that they both have some abnormal embryological development might imply that there may be some common but yet undetected influencing factors between the two diseases.

Firstly, the common dilated vascular channels and foci of interstitial and peritrabecular hemorrhage in FD may probably explain the propensity to develop vascular anomalies [41] such as AVFs [9, 42, 43] and AVMs $[5,8]$. Secondly, another possible explanation for the

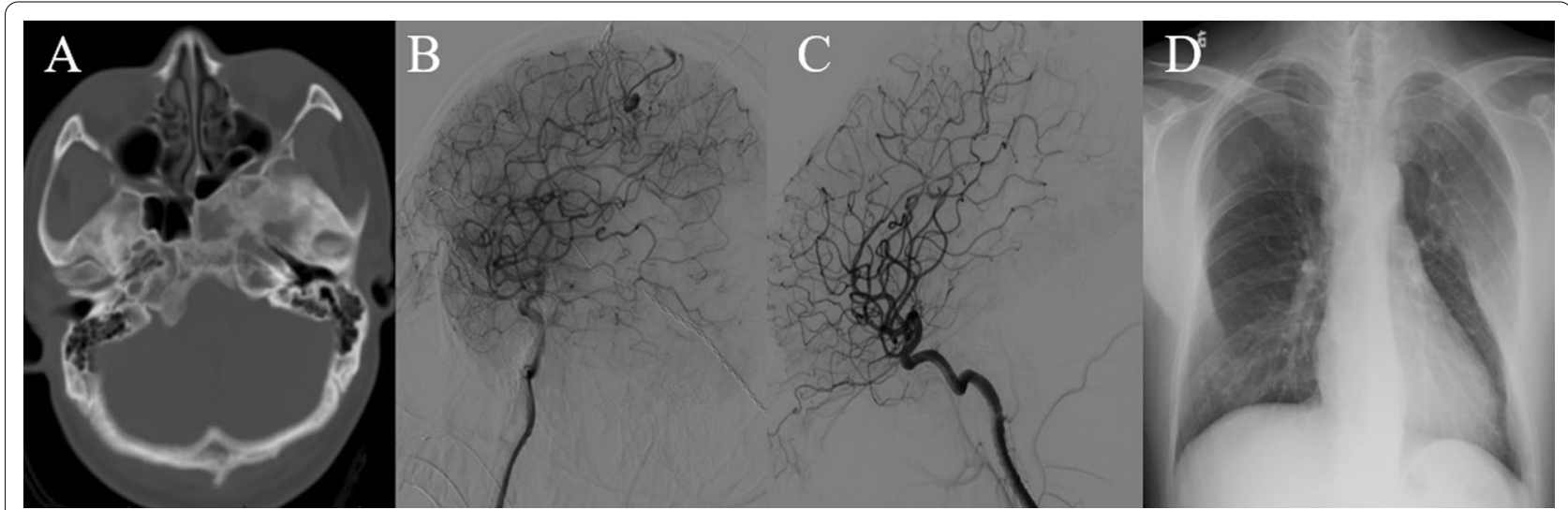

Fig. 3 CT showing FD of the left sphenoid bone (A). DSA showing arteriovenous malformation in the right parietal lobe with right anterior cerebral artery being the major feeding artery and superior sagital sinus drainging (B). The lesion was resected completely (C). Chest X-ray showing FD of multiple ribs (D)
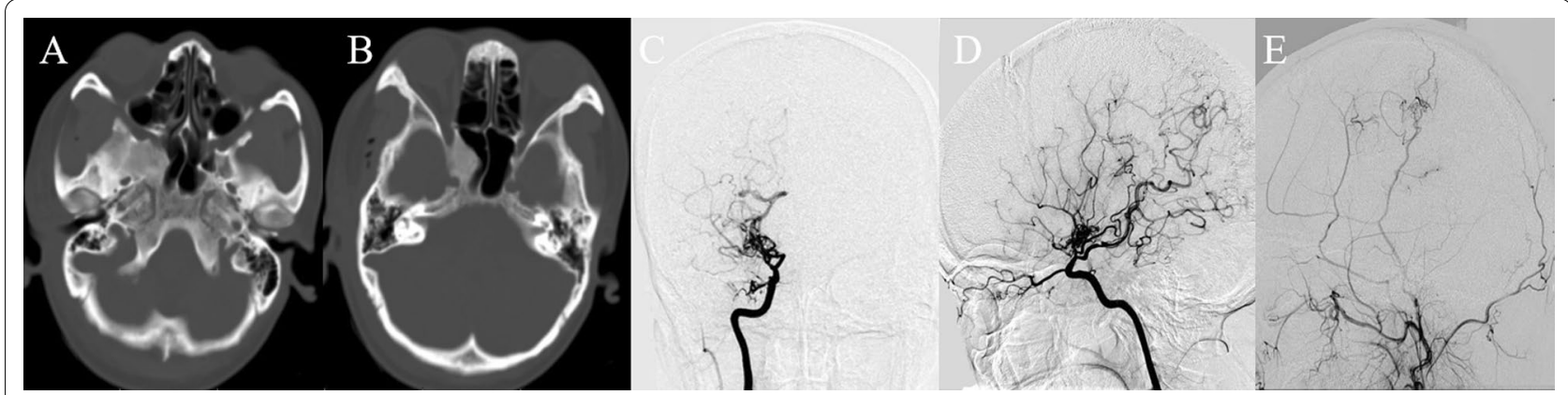

Fig. 4 CT showing FD of local right sphenoid bone (A, B) and DSA showing MMD with the terminal of right internal carotid artery occluded (C, D). Right indirect revascularization was done and after 3 years, the DSA showed neovascularization (E)

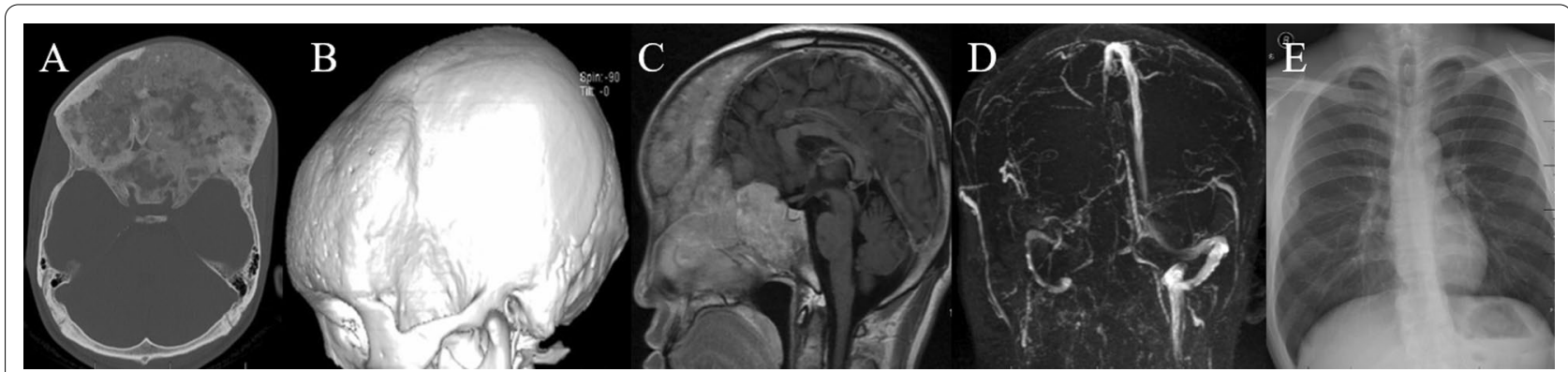

Fig. 5 CT showing FD of Left ethmoid bone, nasal bone, sphenoid bone, bilateral orbits and frontal bones (A, B). MRI showing compression of the brain $(\mathbf{C})$. MRV showing diffuse stenosis of the left venous sinuses $(\mathbf{D})$. Chest $X$ ray showing FD of the right 7 th rib $(E)$ 
coexistence of FD and hemorrhagic cerebrovascular diseases probably lies in the hemodynamics. Most of the CFD involves the skull base especially the sphenoid bone where the circle of willis which is the predilection site of IAs is located on. FD of this site might result in the displacement of the artery thus altering the angle of arterial bifurcations and subsequently contributing to the formation of IAs to some degree. However, since there was no other study focusing on the relationship between craniofacial FD and vascular diseases and consider the lack of hemodynamic evaluations in our case series, we cannot provide solid evidence for our hypothesis.

It is known that FD in the skull base especially in the sphenoid and temporal bones may result in vision and hearing loss due to the constriction of the cranial nerves caused by the hyperostosis of the involved bones, making us wondering whether this disease could have similar impact on the cerebral vessels leading to not only displacement but also encircling of the vessels leading to stenosis even occlusion of the affected vessels. Additionally, the thickening of the bones attributed to craniofacial FD might also result in the narrowing of the cranial capacity resulting in the increase of intracranial pressure and hemodynamic changes, which is thought to be associated with cerebrovascular stenosis/occlusion and the decrease of cerebral perfusion. The encircling of intracranial arteries is probably consistent with the case 6 in our series. The 44-year old male patient suffered from recurrent cerebral ischemic stroke for the occlusion of right internal carotid artery. The reason why the occlusion occurred in a relative young age may be attributed to the extensive FD of the right skull base which may cause constriction of the right internal carotid artery especially in the area of carotid canal through which the internal carotid artery goes into the cranial cavity. And the increase of intracranial pressure resulted from the narrowing of the cranial capacity might aggravate the ischemic situation. In case 5 , the 25-year old boy suffered from extensive stenosis of his left intracranial venous sinus, which might caused by increase of the intracranial pressure. And in case 7, the patient was diagnosed with acute cerebral ischemia without any abnormalies of his cervical and intracranial

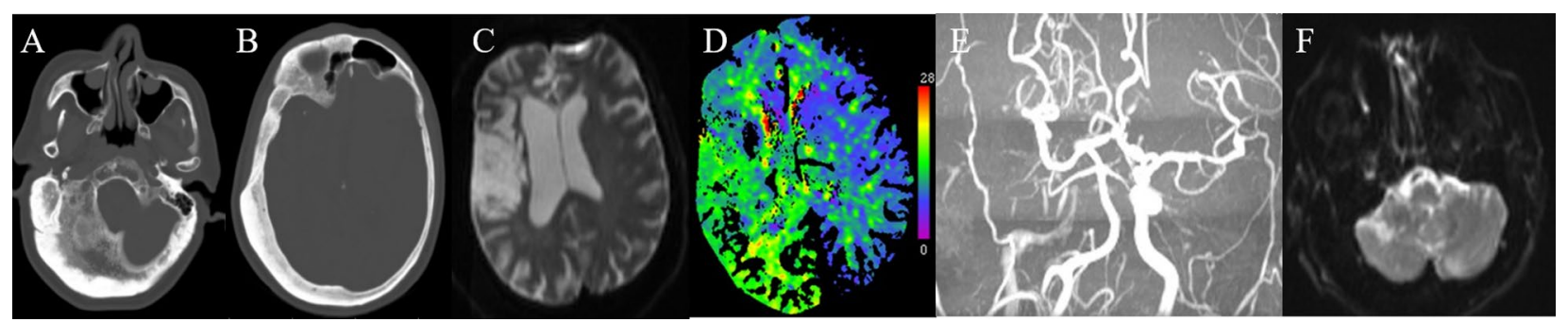

Fig. 6 CT showing extensive FD of right skull bones especially the right skull base (A, B). MRI showing cerebral ischemia of right fronto-temporal lobes (C) and CTP showing diffuse hypoperfusion of the right brain hemisphere (D). MRA showing occlusion of the right internal carotid artery (E). During the 9-year follow-up, his ischemia progressed and MRI showed newly occurred cerebral ischemia of the right cerebellum (F)

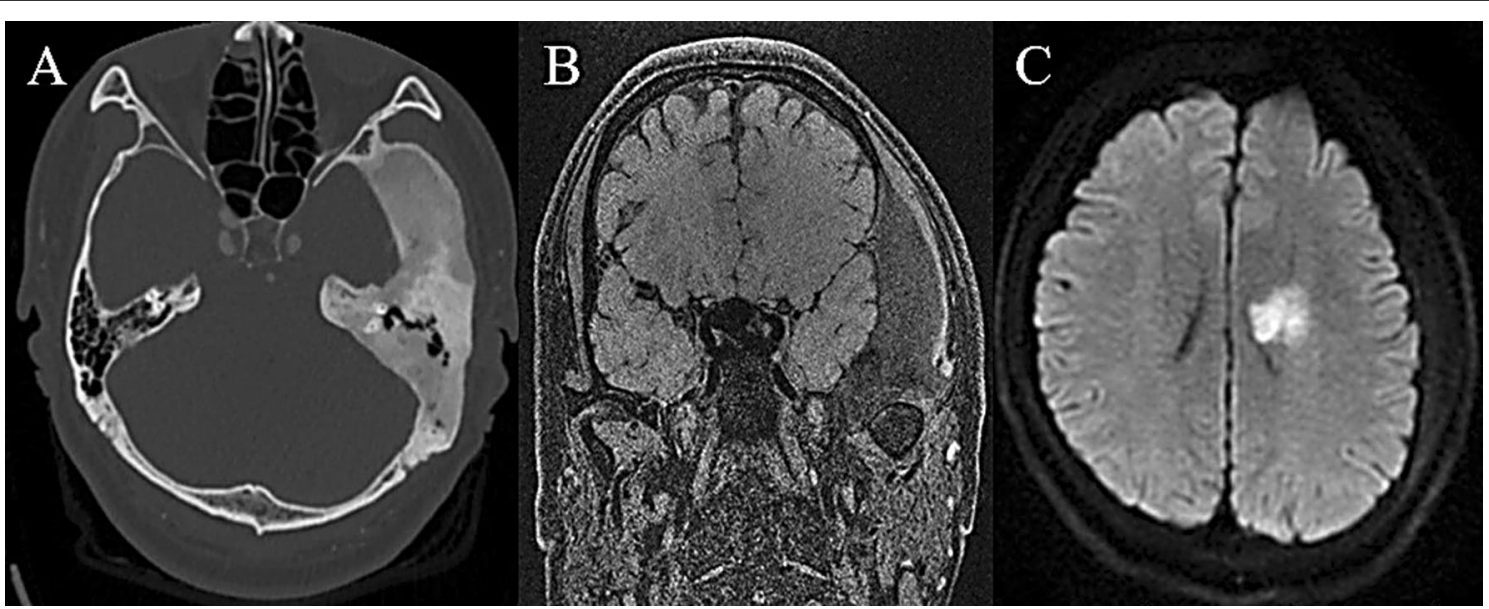

Fig. 7 CT showing FD of the left parietal bone and temporal bone (A). MRI showing compression of the brain tissue (B) and acute cerebral ischemia of the left basal ganglia $(\mathbf{C})$ 
arteries which might be explained by the hypoperfusion caused by the increase of intracranial pressure.

With respect to the management, on the one hand, the coexistence of craniofacial FD may cause difficulties during surgery for the cerebrovascular diseases such as tedious bone work due to extremely thickened bones or massive blood loss due to the hypervascular bones. What's more because of the thickened bone, larger exposure was needed and more angulation of microscope was required to reach the lesion along with increased retraction of ipsilateral cerebellar lobes. Therefore, clinicians need to adopt individualized management for this coexistence. In our series, both craniotomy and endovascular management were adopted unlike in the literature review, only endovascular treatment was done to manage the coexisted vascular diseases. On the other hand, the coexistence of CFD and vascular diseases indicate that clinicians need to fully aware of possible alterations of hemodynamics and intracranial pressure caused by CFD and the resulted CVD which was totally neglected before, and the multidisciplinary team might be needed for the evaluation and management of the disease. It is reasonable and highly recommended for patients with CFD to do throughout examinations evaluating not only the disease burden of FD since it tend to be polyosotic and have multiple clinical manifestations but also the intracranial vessels which might allow the physicians to detect the coexisting vascular diseases on time thus individualizing the treatment strategies, reduce the treatment risks and improve patients' diagnosis.

\section{Limitation}

Firstly, due to the retrospective nature of the article, we did not have access to throughout patient information therefore we could not provide definite explanation for the rare coexistence. Secondly, due to the rareness of CFD, the sample size was fairly small making it unable for us to do further statistical analysis for more evidence and only simple description of the series could be done.

\section{Conclusion}

The coexisting of these lesions in central nervous system reported could not only provide clinicians with further knowledge of FD but also could help them understand the etiology of these lesions. And considering about the possible interaction between these two diseases, it is fair reasonable for patients with CFD to have some screenings and evaluations about CVDs.

\section{Acknowledgements}

Not applicable
Authors' contributions

SXW analyzed and interpreted the patient data and was a major contributor in writing the manuscript. LZ designed the study and revised the manuscript. All authors read and approved the final manuscript.

\section{Funding}

No.

\section{Availability of data and materials}

The datasets generated and/or analysed during the current study are not publicly available due to individual privacy of the patients included but are available from the corresponding author on reasonable request.

\section{Declarations}

\section{Ethics approval and consent to participate}

This study was approved by Institutional Review Board of Beijing Tiantan Hospital, Capital Medical University. Due to the retrospective nature of our study, the board waived the need for written consent.

\section{Consent for publication}

All the patients included signed the consent for publication.

\section{Competing interests}

The authors declare that they have no competing interests.

\section{Author details}

${ }^{1}$ Department of Neurosurgery, Beijing Tiantan Hospital, Capital Medical University, No 119, Nansihuan xilu, Beijing 100070, China. ${ }^{2}$ China National Research Center for Neurological Disease, Beijing, China.

Received: 21 February 2021 Accepted: 24 October 2021

Published online: 04 November 2021

\section{References}

1. Riminucci M, Fisher LW, Shenker A, Spiegel AM, Bianco P, P GR. Fibrous dysplasia of bone in the McCune-Albright syndrome: abnormalities in bone formation. The American journal of pathology. 1997; 151:1587-1600

2. Kelly MH, Brillante B, Collins MT. Pain in fibrous dysplasia of bone: age related changes and the anatomical distribution of skeletal lesions. Osteoporos Int. 2008;19:57-63.

3. Lee JS, FitzGibbon E, Butman JA, Dufresne CR, Kushner H, Wientroub S, Robey PG, Collins MT. Normal vision despite narrowing of the optic canal in fibrous dysplasia. N Engl J Med. 2002;347:1670-6.

4. Scuderi G, Nucci C, Laghi A, Corsi A, Cerulli L. A rare case of McCunealbright syndrome associated with glaucoma retinal degeneration and arteriovenous malformations. Eye (Lond). 1996;10:752-5.

5. MacErlean DP, Shanik DG, Martin EA. Transcatheter embolisation of bone tumour arteriovenous malformations. Br J Radiol. 1978;51:414-9.

6. Huang X, An J, Zhang Y, Cai Z. Intraosseous venous malformations of the zygoma: report of 4 cases and literature review. Ann Otol Rhinol Laryngol. 2017:126(6):505-9.

7. Pan KS, de Castro LF, Roszko KL, Greenberg ED, FitzGibbon EJ, Dufresne CR, Boyce AM, Collins MT. Successful intravascular treatment of an intraosseous arteriovenous fistula in fibrous dysplasia. Calcif Tissue Int. 2020;107(2):195-200.

8. Ohshika S, Yanagisawa M, Tsushima F, Ishibashi Y. Diagnosis and conservative treatment of a rare case of femoral intraosseous arteriovenous malformation in a patient with polyostotic fibrous dysplasia: a case report. Mol Clin Oncol. 2019;10(6):587-91.

9. Ishiguro S, Ikeda M, Shimizu H, Hayashi M. Arteriovenous fistula as an unusual complication of polyostotic fibrous dysplasia of the skull. Surg Neurol. 1985;24:681-4.

10. Settecase F, Nicholson AD, Amans MR, Higashida RT, Halbach W, Cooke DL, Dowd CF, Hetts SW. Onyx embolization of an intraosseous pseudoaneurysm of the middle meningeal artery in a patient with 
meningiomatosis, McCune-Albright syndrome, and gray platelet syndrome. J Neurosurg Pediatr. 2016;17(3):324-9.

11. Frankel J, lanotti F, Powell M, Schon F. Meningioma—an unrecognized complication of fibrous dysplasia of skull? J Neurol Neurosurg Psychiatry. 1989:52:564-7.

12. Bayas A, Naumann M, Wener S, Klaus VT. Meningioma associated with McCune-Albright syndrome. J Neurol. 1999:246:1199-200.

13. Tasar M, Ors F, Yetiser S, Ugurel MS, T. U. Multiple globoid meningiomas associated with craniomandibular fibrous dysplasia: case report. Clin Imaging. 2004; 28:20-22.

14. Banerjee AK, W. B. A subfrontal tumor with the features of plasmacytoma and meningioma. Acta Neuropathol. 1971; 18:84-88.

15. Blanco P, Schaeverbeke T, Baillet L, Leqen L, Bannwarth B, J D. Chondrosarcoma in a patient with McCune-Albright syndrome. Report of a case. Rev Rhum Engl Ed. 1999; 66:177-179.

16. Spencer T, Pan KS, Collins MT, Boyce AM. The clinical spectrum of Mccune-Albright syndrome and its management. Horm Res Paediatr. 2019:92(6):347-56.

17. Ghosal N, Furtado SV, Santosh V, Sridhar M, Hegde AS. Co-existing fibrous dysplasia and atypical lymphoplasmacyte-rich meningioma. Neuropathology. 2007;27(3):269-72.

18. Joseph PL, Robert G, Norman EC, Kricheff II. The angiographic features of fibrous dysplasia of the skull. Radiology. 1969;92:1275-80.

19. Weinstein LS, Shenker A, Gejman PV, Merino MJ, Friedman E, Spiegel AM. Activating mutations of the stimulatory $G$ protein in the McCuneAlbright syndrome. N Engl J Med. 1991;325:1688-95.

20. Weinstein LS. G(s)alpha mutations in fibrous dysplasia and McCuneAlbright syndrome. J Bone Miner Res. 2006;21 (Suppl 2):P120-124.

21. Weinstein LS, Liu J, Sakamoto A, Xie T, Chen M. Minireview: GNAS: normal and abnormal functions. Endocrinology. 2004;145(12):5459-64.

22. Yahui L, Hui Y, Weihua S, Yinhui Z, Channa Z, Yufang Z, Qi P, Rutai H, Chen $\mathrm{J}$. A variant in the endoglin gene is associated with the development of sporadic intracranial aneurysms. Curr Neurovasc Res. 2014;11:294-301.

23. Akiyama K, Narita A, Nakaoka H, Cui T, Takahashi T, Yasuno K, Tajima A, Krischek B, Yamamoto K, Kasuya H, et al. Genome-wide association study to identify genetic variants present in Japanese patients harboring intracranial aneurysms. J Hum Genet. 2010;55(10):656-61.

24. Bilguvar K, Yasuno K, Niemela M, Ruigrok YM, von Und Zu Fraunberg M, van Duijn CM, van den Berg LH, Mane S, Mason CE, Choi M, et al. Susceptibility loci for intracranial aneurysm in European and Japanese populations. Nat Genet. 2008;40(12):1472-7.

25. Brinjikji W, Iyer VN, Yamaki V, Lanzino G, Cloft HJ, Thielen KR, Swanson $\mathrm{KL}$, Wood CP. Neurovascular manifestations of hereditary hemorrhagic telangiectasia: a consecutive series of 376 patients during 15 years. AJNR Am J Neuroradiol. 2016;37(8):1479-86.

26. Foroud T, Koller DL, Lai D, Sauerbeck L, Anderson C, Ko N, Deka R, Mosley $\mathrm{TH}$, Fornage M, Woo D, et al. Genome-wide association study of intracranial aneurysms confirms role of Anril and SOX17 in disease risk. Stroke. 2012;43(11):2846-52.

27. Foroud T, Lai D, Koller D, Van't Hof F, Kurki Ml, Anderson CS, Brown RD Jr, Connolly ES, Eriksson JG, Flaherty M, et al. Genome-wide association study of intracranial aneurysm identifies a new association on chromosome 7. Stroke. 2014:45(11):3194-9.

28. Yang X, Li J, Fang Y, Zhang Z, Jin D, Chen X, Zhao Y, Li M, Huan L, Kent TA et al. Rho guanine nucleotide exchange factor ARHGEF17 Is a risk gene for intracranial aneurysms. Circ Genom Precis Med. 2018;11(7):e002099.
29. Arning A, Jeibmann A, Kohnemann S, Brokinkel B, Ewelt C, Berger K, Wellmann J, Nowak-Gottl U, Stummer W, Stoll M, et al. ADAMTS genes and the risk of cerebral aneurysm. J Neurosurg. 2016;125(2):269-74.

30. Yan J, Hitomi T, Takenaka K, Kato M, Kobayashi H, Okuda H, Harada $\mathrm{KH}$, Koizumi A. Genetic study of intracranial aneurysms. Stroke. 2015;46(3):620-6

31. Du Z, Zheng J, Zhang Z, Wang Y. Review of the endothelial pathogenic mechanism of TIE2-related venous malformation. J Vasc Surg Venous Lymphat Disord. 2017;5(5):740-8.

32. Lim Young H, Bacchiocchi A, Qiu J, Straub R, Bruckner A, Bercovitch L, Narayan D, McNiff J, Ko C, Robinson-Bostom L, et al. GNA14 somatic mutation causes congenital and sporadic vascular tumors by MAPK activation. Am J Hum Genet. 2016;99(2):443-50.

33. Nikolaev SI, Vetiska S, Bonilla X, Boudreau E, Jauhiainen S, Rezai Jahromi B, Khyzha N, DiStefano PV, Suutarinen S, Kiehl TR, et al. Somatic activating KRAS mutations in arteriovenous malformations of the brain. N Engl J Med. 2018;378(3):250-61.

34. Shirley MD, Tang H, Gallione CJ, Baugher JD, Frelin LP, Cohen B, North PE, Marchuk DA, Comi AM, Pevsner J. Sturge-Weber syndrome and port-wine stains caused by somatic mutation in GNAQ. N Engl I Med. 2013;368(21):1971-9.

35. Amary MF, Damato S, Halai D, Eskandarpour M, Berisha F, Bonar F, McCarthy S, Fantin VR, Straley KS, Lobo S, et al. Ollier disease and Maffucci syndrome are caused by somatic mosaic mutations of IDH1 and IDH2. Nat Genet. 2011;43(12):1262-5.

36. Freed D, Stevens EL, Pevsner J. Somatic mosaicism in the human genome Genes (Basel). 2014;5(4):1064-94.

37. Huang S, Guo ZN, Shi M, Yang Y, Rao M. Etiology and pathogenesis of moyamoya disease: an update on disease prevalence. Int I Stroke. 2017;12(3):246-53.

38. Okazaki S, Morimoto T, Kamatani Y, Kamimura T, Kobayashi H, Harada K Tomita T, Higashiyama A, Takahashi JC, Nakagawara J, et al. Moyamoya disease susceptibility variant RNF213 p.R4810K increases the risk of ischemic stroke attributable to large-artery atherosclerosis. Circulation. 2019:139(2):295-8.

39. Chalouhi N, Ali MS, Jabbour PM, Tjoumakaris SI, Gonzalez LF, Rosenwasser RH, Koch WJ, Dumont AS. Biology of intracranial aneurysms: role of inflammation. J Cereb Blood Flow Metab. 2012;32(9):1659-76.

40. Colletti G, Valassina D, Bertossi D, Melchiorre F, Vercellio G, Roberto B. Contemporary management of vascular malformations. J Oral Maxillofac Surg. 2014;72:510-28.

41. Ippolito E, Bray EW, Corsi A, De Maio F, Exner UG, Robey PG. Natural history and treatment of fbrous dysplasia of bone: a multicenter clinicopathologic study promoted by the European Pediatric Orthopaedic Society. J Pediatr Orthop B. 2003;12:155-77.

42. McIntosh HDMD, Gleason WL, Leonard JG. The circulatory dynamics of polyostotic fbrous dysplasia. Am J Med. 1962;32:393-403.

43. The angiographic features of fibrous dysplasia of the skull.

44. Yamashita S, Kimura H, Kohta M, Fujita A, Kohmura E. Thrombosed middle meningeal artery aneurysms mimicking aneurysmal bone cysts in a patient with fibrous dysplasia. World Neurosurg. 2019;130:439-43.

\section{Publisher's Note}

Springer Nature remains neutral with regard to jurisdictional claims in published maps and institutional affiliations. 